Portland State University

PDXScholar

6-2-2017

\title{
Discrimination and Health: Sleep and Racism-related Vigilance in Wave 5 of Americans' Changing Lives Study
}

Jennifer Werekeitzen

Portland State University

Follow this and additional works at: https://pdxscholar.library.pdx.edu/honorstheses

Let us know how access to this document benefits you.

Recommended Citation

Werekeitzen, Jennifer, "Discrimination and Health: Sleep and Racism-related Vigilance in Wave 5 of Americans' Changing Lives Study" (2017). University Honors Theses. Paper 428.

https://doi.org/10.15760/honors.424

This Thesis is brought to you for free and open access. It has been accepted for inclusion in University Honors Theses by an authorized administrator of PDXScholar. Please contact us if we can make this document more accessible: pdxscholar@pdx.edu. 
Discrimination and Health: Sleep and Racism-related Vigilance in Wave 5 of Americans' Changing Lives Study

by

Jennifer Werekeitzen

An undergraduate honors thesis submitted in partial fulfillment of the requirements for the degree of

Bachelor of Science

in

University Honors

and

Psychology

Thesis Adviser

Kerth O'Brien, $\mathrm{PhD}$

Portland State University 


\section{INTRODUCTION}

Sleep is imperative to our health and well-being. Sleep deprivation has been linked to various negative health outcomes including migraines, hypertension, heart disease, diabetes, depression, and obesity (Kim et al., 2001; Strine \& Chapman, 2005; Altman et al., 2012). Its effects can even be seen in the work place through increased industrial accidents and occupational errors (Maia, Grandner, Findley, \& Gurubhagavatula, 2013). Despite this, sleep disturbance is a common problem in the general population (Hublin, Kaprio, \& Koskenvuo, 2001; Holt, Zhang, Sizov, \& Croft, 2015).

Of similar importance and a contributor to the problem with sleep is discrimination. Discrimination can be on the basis of a variety of categories, from age to gender, race, and even religion to name a few. There are various strategies minorities use to deal with such events, one of the most recently emerging in the literature being racism-related vigilance, the act of "mentally preparing for the possibility of experiencing racial discrimination on a day-to-day basis" (Hicken, Lee, Ailshire, Burgard, \& Williams, 2013).

Many disciplines such as social science, public health, and medicine have focused on racial/ethnic disparities and have had significant findings (Hicken et al., 2013). For example, mortality rates for infants and adults are greater for Black Americans than they are for White Americans (James, 1993; Geronimus et al., 1996; Geronimus, et al., 2001; Kramer \& Hogue 2009). Similarly, Black Americans have greater rates of chronic morbidity (Morenoff et al., 2007; Williams et al., 2012). Another finding has been that racial/ethnic disparities are present in sleep with Black adults reporting shorter and longer sleep duration than White adults (Hale \& Do, 2007). This is concerning because research has also shown that sleeping for too little or too 
much is strongly linked to an increase in risk for disease (Ayas, et al., 2003; Patel, et al., 2004; Buxton \& Marcelli, 2010; Knutson, 2013.

Furthermore, previous research has suggested that chronic stress and poor sleep quality go hand in hand due to people having a hard time falling asleep when feeling stressed or preoccupied (Akerstedt et al., 2007; Åkerstedt, et al., 2012). One such source of stress, according to Clark et al., Williams \& Mohammed, and Borrell et al. is racial discrimination $(1999 ; 2010$; 2012).

The link between race and sleep disparity has been well-established; however, the empirical literature is very scarce in articles that explain why these disparities occur. One of the emerging explanations is racism-related vigilance (RRV). Unfortunately, RRV is a very small niche of the greater literature and exploration has been very limited; to our knowledge, only a few other published articles have dealt with RRV and/or the anticipation of ethnic/racial prejudice and stress or sleep (Hicken et al., 2013; Sawyer, Major, Casad, Townsend, \& Mendes, 2012; Hicken, Lee, Morenoff, House, \& Williams, 2014; Nuru-Jeter et al., 2009; Clark, Benkert, \& Flack, 2006; Slopen \& Williams, 2014; Thomas, Ancoli-Israe, \& Dimsdale, 2006)

Hicken et al.'s article from 2013 is the inspiration behind the present manuscript and our goal is to further substantiate their findings to a more general population. They used data from the Chicago Community Adult Health Study and while it was an important pioneering article, we are interested in verifying their findings and applying them to a wider population that comes from the Americans' Changing Lives project. This research is important because if the findings can be verified, future research can focus on the implications and possible solutions.

We begin by taking a look at the different types of discrimination followed by a review of the literature regarding health disparities and finally narrowing into anticipated discrimination 
research, what is known about the possible connection between sleep deprivation in Black Americans versus White Americans and what the relationship is between these and vigilance.

\section{BACKGROUND}

Discrimination

Racial/ethnic discrimination is not the only type of discrimination in the literature. Discrimination on the basis of gender, sexual orientation, disability status, family status, and many other categories exist.

\section{a. Gender}

In a recent meta-analysis from 2015, Koch, D’Mello, \& Sackett found that gender bias continues to be a concern in many work settings. Males are preferred for male-dominated jobs due to the gender-role congruity phenomenon. Providing additional information about the person, which is thought to decrease stereotypes and therefore discrimination, was not enough to reduce gender-role congruity bias. Females are still seen as less competent than males, unless substantial information proves otherwise. In underdeveloped countries where malnutrition is a problem, sons are prioritized in the allocation of food supply more so than daughters (Schwekendiek, 2014). Women are also treated as if they need to be more protected and unable to handle challenges in the work place (King et al., 2012). Similarly, in the world of academia, women are described as more communal and less agentic leading to weaker letters of recommendation and smaller chances of getting hired (Madera, Hebl, Randi, 2009).

Even in serious topics such as sexual harassment, we find differences based on gender: women are believed more often than men (Madera, Podratz, King, \& Hebl, 2007)

\section{b. Sexual Orientation}


Findings from 2002 suggest that police officers observed other members of the force treating homosexual members of the public more negatively than heterosexual individuals and that officers do not always take complaints from LGBT victims as seriously as those made by heterosexual victims (Berstein \& Kostelac). LGBT individuals are also seen as being sick, mentally ill, or insane (Embrick, Walther, \& Wickens, 2007). Furthermore, in the workplace, 8\% of LGB individuals are about twice as likely to report discrimination in the "form of firing, denial of employment, or denial of a promotion" according to Mays \& Cochran (2001).

\section{c. Disability Status}

Years of empirical research has shown that physically disabled individuals are perceived as "quiet, non-egotistical, helpless, hypersensitive, inferior, depressed, distant, shy, unsociable, bitter, nervous, unaggressive, insecure, dependent, unhappy, aloof, submissive, honest, gentlehearted, and unappealing" (Fichten \& Amsel, 1986). Moreover, research also suggests that disabled individuals are "more likely to be viewed as saint-like, courageous, deserving of a break, and less capable of competing with others than nondisabled persons” (Makas, 1988). In general, we see that the literature points to disabled individuals having more undesirable traits attributed to them and as a result greater discrimination.

\section{d. Family Status}

Sabat, Lindsey, King, \& Jones argue that working mothers experience stigmatization due to pregnancy and motherhood being negatively viewed within a workplace setting and this often "leads to discriminatory outcomes" (2016). Working mothers incur a "five percent wage penalty per child" (Anderson et al., 2003; Budig \& England, 2001). Women with children are rated less competent and with less agentic characteristics than women without children (Heilman \& 
Okimoto, 2008). Men with children are encouraged and expected to want to enter high-status positions so as to provide for their children - implying that monetary goods are all they can and should be responsible for (Eagly et al., 2000).

\section{e. Race/Ethnicity}

The difference between "race" and "ethnicity" is not clear and varies across and within countries as well as time. Ethnicity generally takes into account skin tone, ancestry, physical traits, culture, history, and religion (Egan, Knutson, Pereira, \& von Schantz, 2017). According to the American Psychological Association, race is "the category to which others assign individuals on the basis of physical characteristics and the generalizations and stereotypes made as a result." For the purposes of this manuscript, we will use "race/ethnicity" so as to best encompass all categories, however, it is important to note a lot of differences can occur within a single race/ethnicity including "primary language use, country of origin, socioeconomic backgrounds, and cultural practices (Egan et al., 2017).

One area where a lot of race/ethnicity discrimination occurs is the work context (Plaut, Thomas, \& Hebl, 2014). In 2004, a study by Bertrand \& Mullainathan found that individuals with more White American sounding names (such as Emily or Greg) received 50 percent more callbacks for interviews when applying for jobs than individuals with African-American sounding names (such as Lakisha or Jamal). African-American individuals are rated lower in their job performance when their supervisors are White than when their supervisors are Black (Stauffer \& Buckley, 2005). Asian American individuals receive the opposite response: they are evaluated highly for high-status jobs regardless of how good their resume is (King, Madera, Hebl, \& Knight, 2006). In the same study by King et al., they found Black applications were evaluated "negatively even with strong credentials." Finally, in 2013, for every dollar earned by 
a White household, Black households earned 59 cents and Hispanic households earned 70 cents (DeNavas-Walt \& Proctor).

Other forms of ethnic/racial discrimination can be seen in the healthcare field. Compared to White patients, Black patients experience lower quality of care according to Mayr et al. (2010). Similarly, Abramson, Hashemi, \& Sánchez-Jankowski found that African Americans were more likely to perceive discrimination in health care than European Americans (2015).

\section{Health Outcome Disparities due to Discrimination}

While there are many manifestations of the consequences of discrimination, stress and sleep are two significant outcomes that we will be focusing on for this paper. Nevertheless, we continue the background section by expanding on general health outcomes of discrimination before finally focusing the topic of this paper: race/ethnicity discrimination and sleep.

A review from 2015 reported that self-reported measures of discrimination were "related to multiple indicators of health including "hypertension, all-cause mortality, incident asthma, incident breast cancer, and poor mental health" (Lewis, Cogburn, \& Williams). The same review also found that individuals with higher rates of discrimination experienced higher levels of early indicators of clinical disease such as "inflammation, carotid intima-media thickness, visceral fat, obesity, coronary artery calcification, shorter telomeres, and cortisol dysregulation" (Lewis et al., 2015). Lastly, the review found a positive relationship between discrimination experience and health behaviors including "poor sleep quantity and quality, cigarette smoking, and substance use" (Lewis et al., 2015).

The following are a few of the health categories where the literature emphasizes significant differences due to ethnicity/race. This is by no means all-inclusive, but rather serves to highlight the impact race/ethnicity has on health disparities. 


\section{a. Cardiovascular Disease}

Cardiovascular disease is the leading cause of death worldwide (Mensah \& Brown, 2007). Compared with European Americans, African Americans are at increased risk of cardiovascular disease; Asian Americans and Latin Americans are at lower risk of cardiovascular disease (Mensah \& Brown, 2007).

\section{b. Stress}

Evidence from a meta-analysis including almost 150 studies showed that discrimination can result in mental and physical health consequences, one of them being stress (Pascoe $\&$ Richman, 2009). Sawyer et al. found that "participants who believed that their interaction partner held prejudiced attitudes reported greater concern" this shows that simply anticipating prejudice leads to greater psychological stress (2012). Similarly, in 2015 Lewis et al. found that the threat of discrimination is a type of stressor and leads to an "increased cardiovascular response, symptoms of poor mental health, and hypertension."

c. Sleep

Sleep is very important for human health. There is evidence that there is a wellestablished relationship between insufficient sleep and cardiovascular disease (Mullington, Haack, Toth, Serrador, \& Meier-Ewert, 2009). Sleep deprivation is also associated with poor attention and performance deficits. Not surprisingly, sleep problems have been correlated with higher mortality and morbidity (Millington et al., 2009). Similarly, people sleeping less than 6 hours a night are "66\% more likely to have hypertension" than those that sleep $7-8$ hours (Gottlieb et al., 2005). Short sleep duration has also been linked to an "increased risk for future 
coronary heart disease in women, impaired glucose tolerance in men and women, and the development of diabetes in women" (Mullington et al., 2009).

\section{Race/Ethnicity \& Sleep}

Studies linking experiences of discrimination and sleep are limited. Early research from 2006 found that in a sample of 37 African Americans and 56 Caucasian Americans, African Americans had less slow-wave sleep and reported more physical fatigue than Caucasian Americans (Thomas, Ancoli-Israe, \& Dimsdale). In 2013, Lewis and colleagues examined the correlation between chronic everyday discrimination over 4 years and measures of poor sleep (both subjective and objective). In 368 women, they found that chronic everyday discrimination was associated most highly with subjective sleep complaints and sleep continuity problems (one of their objective sleep measures) (Lewis et al., 2013). A later study from 2014 measured selfreported sleep duration as well as racial and nonracial every day and major experiences of discrimination (Slopen \& Williams, 2014). They found that racial everyday discrimination and major experiences of discrimination were associated with shorter sleep. Their results also showed that the findings were independent of concurrent stressors such as acute events, childhood adversity, and financial, community, employment, and relationship stressors (Slopen \& Williams, 2014).

\section{Racism-related Vigilance \& Health}

Recent studies have examined how vigilance or anticipating discrimination might impact health (Lewis et al., 2015). This has allowed for discovery and insight into the impact of stress generated by discrimination. In 2006, Brosschot et al. found that worry, rumination, and anticipatory stress can serve to "prolong and exacerbate the negative effects of stress on health." 
Stress and vigilance are very closely related in that anticipatory stress is reflected in chronic or sustained vigilance (Lewis et al., 2015). Vigilance can then lead to unstable emotional and physiological function that can increase risks for multiple diseases (Brosschot et al., 2006). Furthermore, in African Americans it has been found that "failure to ever completely relax [due to] the constant threat of discrimination and others dangers linked to living in hostile residential context is a contributor to elevated risk of disease" (Lewis et al., 2015) Lindstrom found that in a national sample of adults in Sweden anticipatory ethnic discrimination was linked to lower psychological health (2008). Additionally, Latina college students that anticipated being discriminated against had higher levels of stress and cardiovascular responses (Sawyer et al., 2012).

A study of adults in Baltimore found that African Americans had higher levels of vigilance than Whites had and that vigilance was both positively associated with depressive symptoms and contributed to the Black-White disparity in this outcome (LaVeist et al. 2014). Clark et al. found that vigilance was negatively related to arterial elasticity for boys, but not girls (2006). Similarly, the Hicken et al. study from 2013 that was mentioned earlier in the introduction found that there were significant differences in sleep levels between ethnicities/races, but that these differences were outranked by vigilance. When vigilance is accounted for, race/ethnicity does not play as big a role as vigilance.

As established previously, stress and sleep are related; the more stress present, the more sleeping problems. It follows then that if anticipation of discrimination (vigilance) is the manifestation of stress related to racism, then vigilant individuals will have a harder time sleeping. Our hypothesis is that Black Americans' vigilance levels will be negatively correlated with their sleep quality such that lower vigilance levels will indicate higher sleep quality. 


\section{METHODS}

We used data from the oldest ongoing nationally representative longitudinal study, Americans' Changing Lives (ACL; House, 2014). The ACL is a stratified, multistage areaprobability sample that began in 1986 with a national face-to-face survey of adults ages 25 and up in the continental U.S., with African Americans and people aged 60 and over over-sampled at twice the rate of the others. The ACL focuses on a wide range of topics from social to psychological and behavioral as well as aspects of medical care and environmental exposure. To date, there are 5 waves: Wave 1 (year 1986), Wave 2 (year 1989), Wave 3 (year 1994), Wave 4 (2001), and Wave 5 (2011). Wave 1 began with 3,617 men and women and has had a response rate of $76-83 \%$ response rate throughout the various waves.

For our study, we limited the ACL analytic sample to respondents who were interviewed for the 2011 survey (Wave 5) and identified as Black or White in the original Wave 1 (year 1986). We further limited the data set by analyzing those that responded to vigilance and sleep questions.

\section{Measures}

David Williams and colleagues developed a six-item scale to capture heightened vigilance (Clark et al. 2006, Williams et al. 1997). After respondents reported experiences of everyday discrimination, they were asked:

"In dealing with the experiences that you just told me about, how often do you a) think in advance about the kind of problems that you are likely to experience?; b) try to prepare for possible insults before leaving home?; c) feel that you always have to be careful about your appearance (to get good service or avoid being harassed)?; d) carefully watch what you say and how you say it?; e) carefully observe what happens around you?, and f) try to avoid certain social situations and places?" (Clark et al. 2006). 
The ACL asked participants an abbreviated version of these questions as can be seen below. The responses to the following questions were used to correlate self-reported sleep hours and racism-related vigilance.

Sleep Questions

G19. How much sleep do you usually get in a 24-hour period?

G19a. During the past 4 weeks, how often would you say you have had trouble falling asleep; would you say rarely or never, sometimes, $\underline{\text { often }}$ or almost every day?

G19b. During the past 4 weeks, how often would you say you have woken up in the middle of the night or very early in the morning and found it hard to get back to sleep; would you say

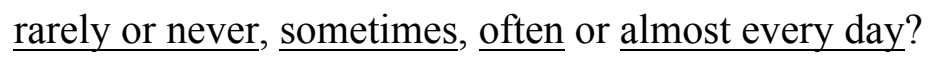

\section{Vigilance Questions}

N20b. In your day-to day life, how often do you do feel that you always have to be very careful about your appearance to get good service or avoid being harassed. Would you say a few times a

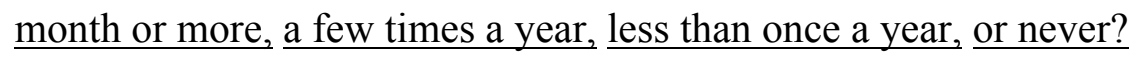

N20c. In your day-to day life, how often do you carefully watch what you say and how you say it. Would you say a few times a month or more, a few times a year, less than once a year, or $\underline{\text { never? }}$

N20d. In your day-to day life, how often do you try to avoid certain social situations and places. Would you say a few times a month or more, a few times a year, less than once a year, or never? 
Each of these questions received a 1-4 rating, 1 "rarely or never" for the sleep questions and "a few times a month or more" for the vigilance questions and 4 being "almost every day" for the sleep questions and "never" for the vigilance questions.

\section{RESULTS}

Please see Appendix A for a summary of the results.

\section{DISCUSSION}

Although moderate, all three correlations between vigilance and trouble falling asleep were significant. Given the literature, this is what was expected. After a day busy with work, school, or other activities, winding down must take place before falling asleep. In this process, it is very possible that any discriminatory events from the day are thought about and it may be harder for this individual to "turn off" their brain. Our findings suggest that someone who is vigilant and constantly on guard may have a hard time shutting down and falling asleep.

We found no significant relationship between hours of sleep and the "watching what you say" measure or the "careful about appearances" measure of vigilance. This makes sense and is to be expected due to the fact that there are a lot of variables that are unaccounted. It is possible for an individual to have go to bed and try to sleep for 8 hours but have trouble falling asleep such that they only sleep 5 hours. Similarly, it is possible someone can have 5 hours to sleep and falls asleep almost immediately. As we can see, the number of hours spent sleeping is not as helpful in looking at vigilance as the act of falling asleep. Similarly, the fact that no significant findings were found in vigilance and trouble falling asleep after waking up makes sense because it maybe be easier to fall asleep once you're sleepy; alternatively, it may be harder to fall asleep 
if you aren't sleepy anymore.

One possible explanation for the lack of results all across the board is the fact that ethnic identity plays a big role in difficulty sleeping. In 2006, Thomas and colleagues found that there was a significant relationship between ethnic identity and sleep latency, indicating that individuals who felt more connected to their ethnic group had more difficulty falling asleep. These observations suggest that the effects of stress related to one's ethnic group membership carry over into sleep and provide an explanation for lack of results as well as a possible area of future research.

\section{LIMITATIONS}

There have been speculations about whether discrimination research should take a one stage or two stage approach (Lewis et al., 2015). A one stage approach is one in which respondents are explicitly asked to report on "racial discrimination" or asked questions with the qualifier, "because of your race" (Lewis et al., 2015). The biggest criticism with this technique is that it can inadvertently motivate responders to report information they believe the interview wants to hear leading to interviewer effects (Lewis et al., 2015). Although the ACL did not use a one stage approach when asking questions regarding discrimination experiences, the questions about vigilance were under the category "discrimination" in the study questionnaire and were asked immediately following a question that asked them to speculate about why they have been discriminated against. It is possible, although unlikely, that after answering such questions the interviewee felt compelled to answer that they had trouble sleeping.

Secondly, self-report data have also been criticized given their subjective nature (Lewis et al., 2015). When dealing with self-report data, we "assume the individual reporting the 
experience has all available information about a given interaction and is able to accurately distinguish between racial discrimination and other types of interpersonal mistreatment" even if this might not always be the case.

Another limitation to this study is that occupation was not included as a control predictor variable. Prior literature has found that there are some careers that are higher in stress levels. Since stress levels and vigilance are correlated, it makes sense that people with high stress jobs may have a harder time relaxing and falling asleep.

Despite these limitations, the present analysis offers important exploratory findings. Given the infancy of this field, it is imperative to start with what is available and confirm findings to determine whether this topic is worthy of further pursuit and that is exactly what this manuscript accomplishes. This manuscript furthers the previous study applicable to individuals from Chicago (Hicken et al., 2013) by using a national survey such as Americans' Changing Lives. 
Acknowledgements.

Data for this project were made available from the Americans' Changing Lives (ACL) project of The University of Michigan (House, 2014). The ACL is study 4690 of the Inter-university Consortium for Political and Social Research (ICPSR) and was funded by the U.S. Department of Health and Human Services, National Institutes of Health, National Institute on Aging (AG05561). The author thanks study respondents, investigators and archivists for making these data available. 
Appendix: Results of Data Analysis

Because the author of this honors thesis did not, herself, conduct the data analyses but rather the thesis advisor conducted them, findings are presented in this Appendix. Table 1 presents means and standard deviations for our variables of interest. Table 2 presents intercorrelations of responses to questions about sleep and vigilance.

Table 1: Means and standard deviations for sleep and vigilance variables $(\mathrm{N}=355)$

Sleep items

G19. How much sleep (hours)

G19a. Trouble falling asleep

G19b. Waking up early

Vigilance items

N20b. Careful about appearance

N20c. Watch what you say

N20d. Avoid certain situations
Mean (s.d.)

$7.37(2.264)$

$1.86(.948)$

$2.04(.969)$

$3.15(1.126)$

$2.39(1.242)$

$2.77(1.152)$ 
Appendix (continued)

Table 2: Intercorrelations of responses to sleep questions with responses to vigilance questions $(\mathrm{N}=355)$

\begin{tabular}{|l|l|l|l|}
\hline & How much sleep & Trouble falling & Waking up early \\
\hline Careful about appearance & .075 & $-.125^{*}$ & \\
\hline Watch what you say & $.122 *$ & $-.144 *$ & $-.145 *$ \\
\hline Avoid certain situations & $.101+$ & $-.124 *$ & -.047 \\
\hline
\end{tabular}

Notes. Pearson correlations. ${ }^{*}$ indicates $p<.05$ and + indicates $.05 \leq p<.10$ 


\section{References}

Abramson, C. M., Hashemi, M., \& Sánchez-Jankowski, M. (2015). Perceived discrimination in U.S. healthcare: Charting the effects of key social characteristics within and across racial groups. Preventive Medicine Reports, 2, 615-621. http://doi.org/10.1016/j.pmedr.2015. 07.006

Altman NG, Izci-Balserak B, Schopfer E, Jackson N, Rattanaumpawan P, Gehrman PR, Patel NP, Grandner MA (2012) Sleep duration versus sleep insufficiency as predictors of cardiometabolic health outcomes. Sleep Medicine 13(10):1261-1270

Americans' Changing Lives. About the ACL: Understanding Social Disparities in Health and Aging the Americans' Changing Lives Study. Retrieved from http://www.isr.umich.edu/ acl/index.htm

Anderson, D. J., Binder, M., \& Krause, K. (2003). The motherhood wage penalty revisited: Experience, heterogeneity, work effort, and work-schedule flexibility. Industrial and Labor Relations Review, 56, 273-294.

Ayas, N.T., White, D.P., Manson, J.E., Stampfer, M.J., Speizer, F.E., Malhotra, A., Hu, F.B. A (2003) Prospective Study of Sleep Duration and Coronary Heart Disease in Women. Archives of Internal Medicine.163(2):205-209. doi:10.1001/archinte.163.2.205

Bernstein, M., \& Kostelac, C. (2002). Lavender and blue: Attitudes about homosexuality and behavior toward lesbians and gay men among police officers. Journal of Contemporary Criminal Justice, 18(3), 302-328. doi:http://dx.doi.org.proxy.lib.pdx.edu/10.1177/ 1043986202018003006

Bertrand, M. \& Mullainathan, S. (2004). "Are Emily And Greg More Employable Than 
Lakisha And Jamal? A Field Experiment On Labor Market Discrimination," American Economic Review, 94(4), 991-1013.

Brosschot JF, Gerin W, Thayer JF. (2006). The perseverative cognition hypothesis: a review of worry, prolonged stress-related physiological activation, and health. Journal of Psychosomatic Research. 60:113-24

Budig, M. J., \& England, P. (2001). The wage penalty for motherhood. American Sociological Review, 66, 204-225.

Buxton, O. M., \& Marcelli, E. (2010). Short and long sleep are positively associated with obesity, diabetes, hypertension, and cardiovascular disease among adults in the United States. Social Science and Medicine, 71(5), 1027-1036.

Clark, R., Benkert, R. A., \& Flack, J. M. (2006). Large arterial elasticity varies as a function of gender and racism-related vigilance in black youth. Journal of Adolescent Health, 39(4), 562-569. doi:http://dx.doi.org.proxy.lib.pdx.edu/10.1016/j.jadohealth.2006.02.012

DeNavas-Walt C, Proctor BD. (2014). Income and poverty in the United States. US Census Bureau. https://www-census-gov.proxy.lib.pdx.edu/content/dam/Census/library/ publications/2014/demo/p60-249.pdf.

Eagly, A. H., Wood, W., \& Diekman, A. B. (2000). Social role theory of sex differences and similarities: A current appraisal. In T. Eckes, \& H. M. Trautner (Eds.), The developmental social psychology of gender; the developmental social psychology of gender (pp. 123-174, Chapter xiv, 470 Pages) Lawrence Erlbaum Associates Publishers, Mahwah, NJ. Retrieved from http://stats.lib.pdx.edu/proxy.php?url=http://search. proquest.com.proxy.lib.pdx.edu/docview/619460868?accountid=13265

Egan, K. J., Knutson, K. L., Pereira, A. C., \& von Schantz, M. (2017). The role of race and 
ethnicity in sleep, circadian rhythms and cardiovascular health. Sleep Medicine

Reviews, 33, 70-78. doi:http://dx.doi.org/10.1016/j.smrv.2016.05.004

Embrick, D. G., Walther, C. S., \& Wickens, C. M. (2007). Working class masculinity: Keeping gay men and lesbians out of the workplace. Sex Roles, 56(11-12), 757-766. doi:http://dx. doiorg.proxy.lib.pdx.edu/10.1007/s11199-007-9234-0

Gottlieb, D. J., Punjabi, N. M., Newman, A. B., Resnick, H. E., Redline, S., Baldwin, C. M., \& Nieto F. J. (2005). Association of sleep time with diabetes mellitus and impaired glucose tolerance. Archives of Internal Medicine. 165(8):863-7.

Guidelines on multicultural education, training, research, practice, and organizational change for Psychologists. American Psychological Association Washington DC US American Psychologist, Vol 58(5), May 2003, 377-402. http://dx.doi.org/10.1037/0003066X.58.5.377

Hale, L., \& Do, D. P. (2007). Racial Differences in Self-Reports of Sleep Duration in a Population-Based Study. Sleep, 30(9), 1096-1103. PMCID: PMC197839

Heilman, M. E., \& Okimoto, T. G. (2008). Motherhood: A potential source of bias in employment decisions. Journal of Applied Psychology, 93(1), 189-198. doi:http://dx.doi. org.proxy.lib.pdx.edu/10.1037/0021-9010.93.1.189

Hicken, M. T., Lee, H., Morenoff, J., House, J. S., \& Williams, D. R. (2014). Racial/ethnic disparities in hypertension prevalence: Reconsidering the role of chronic stress. American Journal of Public Health, 104(1), 117-123. doi:http://dx.doi.org.proxy.lib.pdx.edu/10. 2105/AJPH.2013.301395

Hicken, M. T., Lee, H., Ailshire, J., Burgard, S. A., \& Williams, D. R. (2013). "Every shut eye, 
ain't sleep": The role of racism-related vigilance in Racial/Ethnic disparities in sleep difficulty. Race and Social Problems, 5(2), 100-112. doi:http://dx.doi.org.proxy.lib.pdx. edu/10.1007/s12552-013-9095-9

Holt JB, Zhang X, Sizov N, Croft JB (2015) Airport noise and self-reported sleep insufficiency, United States, 2008 and 2009. Preventing Chronic Disease 12, E49

House, J.S. (2014). Americans' Changing Lives: Waves I, II, III, IV, and V, 1986, 1989, 1994, 2002, and 2011. ICPSR04690-v7. Ann Arbor, MI: Inter-university Consortium for Political and Social Research [distributor], 2014-09-09. https://doi.org/10.3886/ ICPSR04690.v7

Hublin C, Kaprio J, Partinen M, Koskenvuo M (2001) Insufficient sleep-a population-based study in adults. Sleep 24(4):392-400

Kim, J., Cho, S., Kim, W., Yang, K. I., Yun, C., \& Chu, M. K. (2017). Insufficient sleep is prevalent among migraineurs: A population-based study. The Journal of Headache and Pain, 18, 8. doi:http://dx.doi.org.proxy.lib.pdx.edu/10.1186/s10194-017-0756-8

King, E. B., Botsford, W., Hebl, M. R., Kazama, S., Dawson, J. F., \& Perkins, A. (2013). "Benevolent sexism at work: Gender differences in the distribution of challenging developmental experiences": Erratum. Journal of Management, 39(4), 1-1062. doi:http://dx.doi.org.proxy.lib.pdx.edu/10.1177/0149206313482435

Koch, A. J., D'Mello, S. D., \& Sackett, P. R. (2015). A meta-analysis of gender stereotypes and bias in experimental simulations of employment decision making. Journal of Applied Psychology, 100(1), 128-161. doi:http://dx.doi.org.proxy.lib.pdx.edu/10.1037/a0036734

Knutson, K. L. (2013). Sociodemographic and cultural determinants of sleep deficiency: Implications for cardiometabolic disease risk. Social Science and Medicine, 79, 7-15. 
Lewis TT, Cogburn CD, Williams DR. (2015). Self-reported experiences of discrimination and health. Annual Review of Clinical Psychology. 11:407-440.

Lewis, T. T., Troxel, W. M., Kravitz, H. M., Bromberger, J. T., Matthews, K. A., \& Hall, M. H. (2013). Chronic exposure to everyday discrimination and sleep in a multiethnic sample of middle-aged women. Health Psychology, 32(7), 810-819. doi: http://dx.doi.org.proxy.lib. pdx.edu/10.1037/a0029938

Lindstrom M. 2008. Social capital, anticipated ethnic discrimination and self-reported psychological health: a population-based study. Social Science Medicine. 66:1-13

Madera, J. M., Hebl, M. R., \& Martin, R. C. (2009). Gender and letters of recommendation for academia: Agentic and communal differences. Journal of Applied Psychology, 94(6), 1591-1599. doi:http://dx.doi.org.proxy.lib.pdx.edu/10.1037/a0016539

Madera, J. M., Podratz, K. E., King, E. B., \& Hebl, M. R. (2007). Schematic responses to sexual harassment complainants: The influence of gender and physical attractiveness. Sex Roles: A Journal of Research, 56(3-4), 223-230. doi:http://dx.doi.org.proxy.lib.pdx.edu/ $10.1007 /$ s11199-006-9165-1

Maia Q, Grandner MA, Findley J, Gurubhagavatula I (2013) Short and long sleep duration and risk of drowsy driving and the role of subjective sleep insufficiency. Accident Analysis and Prevention 59:618-622

Makas, E. (1988). Positive attitudes toward disabled people: Disabled and nondisabled persons' perspectives. Journal of Social Issues, 44(1), 49-61. doi:http://dx.doi.org.proxy.lib.pdx. edu/10.1111/j.1540-4560.1988.tb02048.x

Mayr, F. B., Yende, S., D’Angelo, G., Barnato, A. E., Kellum, J. A., Weissfeld, L., ... Angus, D. 
C. (2010). Do hospitals provide lower quality of care to black patients for pneumonia? Critical Care Medicine, 38(3), 759-765.

Mays, V. M., \& Cochran, S. D. (2001). Mental health correlates of perceived discrimination among lesbian, gay, and bisexual adults in the united states. American Journal of Public Health, 91(11), 1869-1876. doi:http://dx.doi.org.proxy.lib.pdx.edu/10.2105/AJPH.91.11. 1869

Mensah, G. A. \& Brown, D.W. (2007). “An Overview of Cardiovascular Disease Burden In The United States. Health Affairs 26, 38-48. doi: 10.1377/hlthaff.26.1.38

Mullington, J. M., Haack, M., Toth, M., Serrador, J., \& Meier-Ewert, H. (2009). Cardiovascular, Inflammatory and Metabolic Consequences of Sleep Deprivation. Progress in Cardiovascular Diseases, 51(4), 294-302. http://doi.org/10.1016/j.pcad.2008.10.003

Myers HF, Lewis TT, Parker-Dominguez T. 2003. Stress, coping and minority health: biopsychosocial perspectives on ethnic health disparities. In Handbook of Racial \& Ethnic Minority Psychology, ed. G Bernal, J Trimble, K Burlew, FTL Leong, pp. $377-$ 400. Thousand Oaks, CA: Sage

Nuru-Jeter, A., Dominguez, T. P., Hammond, W. P., Leu, J., Skaff, M., Egerter, S., . . . Braveman, P. (2009). "It's the skin you're in": African-American women talk about their experiences of racism. An exploratory study to develop measures of racism for birth outcome studies. Maternal and Child Health Journal, 13(1), 29-39. doi:http://dx.doi.org.proxy.lib.pdx.edu/10.1007/s10995-008-0357-x

Pascoe, E. A., \& Richman, L. S. (2009). Perceived Discrimination and Health: A Meta-Analytic Review. Psychological Bulletin, 135(4), 531-554. http://doi.org/10.1037/a0016059

Patel, S. R., Ayas, N. T., Malhotra, M.R., White, D. P., Schernhammer, E. S., Speizer, F. E., 
Stampfer, M. J., \& Hu, F. B. (2004). A prospective study of sleep duration and mortality risk in women. Sleep, 27(3), 440-444.

Plaut, V. C., Thomas, K. M., \& Hebl, M. R. (2014). Race and ethnicity in the workplace: Spotlighting the perspectives of historically stigmatized groups. Cultural Diversity and Ethnic Minority Psychology, 20(4), 479-482. doi:http://dx.doi.org.proxy.lib.pdx.edu/10. $1037 / \mathrm{a} 0037544$

Sabat, I. E., Lindsey, A. P., King, E. B., \& Jones, K. P. (2016). Understanding and overcoming challenges faced by working mothers: A theoretical and empirical review. In C. Spitzmueller, \& R. A. Matthews (Eds.), Research perspectives on work and the transition to motherhood; research perspectives on work and the transition to motherhood (pp. 931, Chapter x, 294 Pages) Springer International Publishing, Cham. doi:http://dx.doi.org. proxy.lib.pdx.edu/10.1007/978-3-319-41121-7_2

Sawyer, P. J., Major, B., Casad, B. J., Townsend, S. S. M., \& Mendes, W. B. (2012). Discrimination and the stress response: Psychological and physiological consequences of anticipating prejudice in interethnic interactions. American Journal of Public Health, 102(5), 1020-1026. doi:http://dx.doi.org.proxy.lib.pdx.edu/10.2105/AJPH.2011. 300620

Schwekendiek, D. (2014). A worldwide study on gender differences in chronic undernutrition of children. International Journal of Child Health and Human Development, 7(1), 75-87. Retrieved from http://stats.lib.pdx.edu/proxy.php?url=http://search.proquest.com.proxy. lib.pdx.edu/docview/1560817547?accountid=13265

Slopen, N., \& Williams, D. R. (2014). Discrimination, other psychosocial stressors, and selfreported sleep duration and difficulties. Sleep, 37(1), 147-156. http://doi.org/10.5665/ 
sleep.3326

Stauffer, J. M., \& Buckley, M. R. (2005). The existence and nature of racial bias in supervisory ratings. Journal of Applied Psychology, 90(3), 586-591. doi:http://dx.doi.org. proxy.lib.pdx.edu/10.1037/0021-9010.90.3.586

Strine TW, Chapman DP (2005) Associations of frequent sleep insufficiency with health-related quality of life and health behaviors. Sleep Medicine 6(1):23-27

Williams, D. R., John, D. A., Oyserman, D., Sonnega, J., Mohammed, S. A., \& Jackson, J. S. (2012). Research on Discrimination and Health: An Exploratory Study of Unresolved Conceptual and Measurement Issues. American Journal of Public Health, 102(5), 975978. http://doi.org/10.2105/AJPH.2012.300702

Williams D.R., Yu Y., Jackson J.S., Anderson N.B. (1997). Racial differences in physical and mental health: Socioeconomic status, stress, and discrimination. Journal of Health Psychology. 2:335-51

Williams DR, Wyatt R. (2015). Racial bias in health care and health challenges and opportunities. JAMA. 314(6):555-556. doi:10.1001/jama.2015.9260 